\title{
Incorporating word-of-mouth effects in estimating customer lifetime value
}

Received (in revised form): 13th September, 2006

\section{Jonathan Lee}

is Associate Professor of Marketing in College of Business Administration at California State University, Long Beach. He has also been a faculty at Indiana University and the University of Southern California. He teaches in the areas of marketing research, decision models in marketing, and customer relationships management and his research interest is in the areas of consumer choice models, B2B marketing, and customer equity management. He has published articles in the Management Science, Marketing Science, and Journal of Consumer Research.

\section{Janghyuk Lee}

is an assistant professor of Marketing at Korea University, Business School. His research interests are in customer lifetime value management and internet marketing. He has published articles in Marketing Science, Journal of Services Marketing and Seoul Journal of Business. Before joining Korea University, he worked for Samsung Electronics Europe as a senior marketing analyst from 1999 to 2001 and taught at HEC School of Management, Paris from 2001 to 2005.

\section{Lawrence Feick}

is Professor of Business Administration at the Joseph M. Katz Graduate School of Business at the University of Pittsburgh where he has been a faculty member since 1982. He has published articles in the Journal of Consumer Research, International Journal of Research in Marketing, Journal of Marketing, Journal of Marketing Research, Journal of Retailing, Psychological Bulletin, and Public Opinion Quarterly. He has served as a consultant to a number of profit and non-profit firms, including Eastman Kodak, General Motors, and Newsweek. He has been a visiting professor at the University of Augsburg (Germany), Czech Management Center (Czech Republic), International Management Center (Hungary), Comenius University (Slovak Republic), and Universidad Santa Maria (Ecuador).

Keywords customer lifetime value, word of mouth, acquisition cost, customer valuation, customer loyalty

Abstract The benefit of managing customer relationship by inputs (acquisition and retention costs) and outputs (revenues) for each customer is that marketing managers can better prioritise their efforts by examining the return on marketing investment and thus better differentiate customers by their relative benefits and costs. Valuing customers and measuring marketing effect using only direct financial contributions, however, carries a potential risk of misleading marketing managers since much of the relationship-based indicators are latent such as word of mouth (WOM) but still contribute substantially to customer lifetime value (CLV). In this paper, based on the company data and simulation, we empirically investigate the effect of WOM in estimating CLV. Managerial implications and future research directions are discussed. Journal of Database Marketing \& Customer Strategy Management (2006) 14, 29-39. doi:10.1057/palgrave.dbm.3250033

Jonathan Lee College of Business Administration California State University Long Beach 1250 Bellflower Blvd. Long Beach, CA 90840-8503, USA Tel: + 1562985 4562; Fax: +1 562985 5543; e-mail: jlee6@csulb.edu

\section{INTRODUCTION}

The customer lifetime value (CLV) approach examines customer value over time by comparing acquisition and retention costs to revenue contribution, thus changing the marketing focus from a static, single-transaction model to one that is dynamic, incorporating a series of transactions. In addition, the level of analysis often is refocused from the mass market or segment to the individual customer, typically allowing for customer heterogeneity. By introducing the idea of a customer lifetime and its discounted value, the CLV 
framework shifts attention from a single transaction perspective to one of continuous relationships and encourage research on the link between customer satisfaction and loyalty $^{1-4}$ and profitability. ${ }^{4-6}$

The basic driver of CLV is largely based on the economics of loyalty. Reichheld ${ }^{7}$ identifies four major sources of loyalty that affect the incremental value of customers: (1) revenue growth over time through increases in customer spending, often as a consequence of cross and up-selling, (2) cost reduction by improving the efficiency of serving existing customers and of recruiting new ones, (3) price premiums extracted for value-added services, and (4) revenue increases originating from new customers acquired from referrals as existing customers spread positive word of mouth (WOM) to their family, friends, and acquaintances. Existing CLV models focus mainly on the first three elements of the economics of loyalty: direct revenue and cost generating ones that appear tangibly in the profit and loss statement of the firm. ${ }^{8-10}$

Although widely recognised for its practices under various forms, referral effects are not systematically integrated into CLV management, which may mislead managers to underestimate the lifetime value of customers with low direct financial contribution but with high positive WOM behaviour.

In this paper, we analyse the impact of WOM contribution to CLV by focusing on the savings in customer acquisition cost through WOM. In modelling customer acquisition, we take into account two types of acquisitions: the one generated by market growth, which results in the net increase of new customers, and the other through the replacement of existing customers due to customer churn. Both effects are integrated into a single framework to assess the WOM contribution to CLV, not explicitly examined in previous research. We find a substantial increase in the low revenue/high WOM segment, where its contribution is raised from 11 to 18 per cent, a lift of 102 per cent per customer. Later we also present an extended simulation augmenting the actual data and the results highlight the importance of managing WOM especially in markets with high growth rate and intense competition.

\section{THEORETICAL FRAMEWORK}

\section{WOM and acquisition cost savings}

Dating back to the work of Katz and Lazarsfeld, ${ }^{11}$ interpersonal influence in purchase has been acknowledged as critically important in consumer decision making and choice. The literature notes that WOM affects brand awareness, attitudes, preferences, consideration set composition, and choice. ${ }^{12-14}$ Previous research tells us that the impact of WOM is substantial, but varies among product categories. ${ }^{15}$ For example, nearly half of consumers rely on WOM in choosing a new doctor, while fewer than 20 per cent rely on WOM for a personal loan. ${ }^{16}$ Some previous findings report the impact of WOM in various contexts: a survey in Sweden (with 92,273 observations) and the US (with 37,340 observations) indicates that those who transmitted WOM told on average 9.49 and 7.88 others, respectively. The US Office of Consumer Affairs suggested that satisfied customers for consumer services are likely to tell five others. ${ }^{17}$ Bowman and Narayandas ${ }^{18}$ report that customer-initiated contacts such as product inquiries, requests for refunds, and product complaints have a significant impact on WOM frequency. Based on the data from seven US consumer goods manufacturers, they found that 57 per cent of the sample told someone about their experience and the median number of people told was three.

The contribution of WOM to CLV can be partially assessed by measuring company's spending on customer acquisition.

Companies incur large upfront expenditures to attract customers. These costs include advertising directed at potential customers and salesforce costs: commissions on sales to new customers and salesforce overhead. ${ }^{7}$ 
Since many of those targeted do not become customers, the cost per acquired customer is higher. Bolton ${ }^{1}$ noted that on average $\$ 600$ per customer was spent to acquire new mobile phone subscribers in 1991. Reichheld ${ }^{7}$ reports average acquisition cost (including the costs of direct mail, credit evaluation, card issuance, and modification of databases) per new credit card customer of between $\$ 50$ and $\$ 100$.

\section{Incorporating WOM effects into CLV}

The impact of WOM on CLV is

incorporated in two ways: (i) through the variation of acquisition cost to substitute the customer churns, and (ii) through the savings of acquisition cost of customers accrued by the market growth. To account for the heterogeneity in WOM intentions, we adopt a segment-level analysis. We assume that each segment needs to replace defected customers to make the impact comparative across segments. We assume that the WOM savings is accrued to new customers who are the recipients of the WOM from existing customers. WOM saving per segment is based on the proportion of WOM intent and a segment-level effect ratio given as

$$
\begin{aligned}
\text { WOM Savings }_{\mathrm{t}}^{\mathrm{s}} & =\underbrace{(\text { Total Acq_Cost } \times \text { Average WOM intent })}_{\text {aggregate saving }} \\
& \times \underbrace{\left.\sum_{s=1}^{\exp (\text { WOM intent }} \mathrm{s}_{\mathrm{s}}\right)}_{\text {segment }- \text { level effect ratio }}
\end{aligned}
$$

We use the logit ratio of WOM intent for each segment to reflect the results of Anderson,19 which showed a U-shaped relationship between satisfaction and WOM transmission having a sharp increase on the right extreme of the scale.

Given $S$ number of segments and the duration $T$, we have a modified equation for CLV incorporating the WOM effect at the segment-level as

$$
\text { CLV }=\sum_{\mathrm{s}=1}^{\mathrm{S}} \sum_{\mathrm{t}=1}^{\mathrm{T}} \frac{\text { Revenue }_{\mathrm{t}}^{\mathrm{s}}-\operatorname{Cost}_{\mathrm{t}}^{\mathrm{s}}}{(1+\mathrm{d})^{\mathrm{t}}}
$$

where

$$
\begin{aligned}
\text { Revenue }_{t}^{s} & =\text { Customer }_{t}^{s} \\
& \times \text { Average Revenue }_{s} \\
& =\left(\text { Retained_Customer }_{t}^{s}\right. \\
& + \text { New_Customer } \\
& \text { Newerage Revenue } \\
& \times \text { Avera }_{s}
\end{aligned}
$$

and the total cost of acquisition and retention adjusted using the Equation (1),

$$
\begin{aligned}
\operatorname{Cost}_{t}{ }^{s}= & \text { Acq_COst }_{t}{ }^{s}+\text { Ret_Cost }_{t}{ }^{s} \\
& - \text { WOM Savings } s_{t}^{s}
\end{aligned}
$$

Equations (2)-(3) is a combination of the basic structural model of Berger and $\mathrm{Nasr}^{8}$ and the customer migration model of Dwyer $^{20}$ with some minor modifications. This model retains the basic structure having revenue and cost streams discounted for the time value of money and includes the dynamics of a migration model inside these streams. The number of customers in each segment, Customer ${ }_{t}^{s}$, remains the same at a given period but increases over time based on the market growth rate so that

Customer ${ }_{t}^{s}=$ Customer $_{t}^{s} \times(1+$ growth rate $)$.

As the number of retained customers varies from one segment to another according to its segment-level defection rate, the number of new customers that need to be acquired also varies and hence the cost of acquisition differs across segments. The cost stream for each segment takes into account the WOM effect shown in Equation (4).

\section{DATA AND EMPIRICAL STUDY}

In this section, we empirically examine the link between referral intent and customer retention of a French mobile telephone service provider in order to assess the impact of WOM on CLV through retention. Mobile telephone service has a number of advantages in analysing CLV. First, the mobile phone service is characterised as a continuous sales transaction in which customers with long duration are considered as loyalty. In other industries such as retailers, hotels, and airlines where sales 
transactions are discrete, customer duration with the same service provider does not necessarily explain customer loyalty. Second, customers are typically single brand users. That is, except for some profession-based cases, most customers do not carry multiple mobile phones at a time. The single brand usage simplifies the analysis since it then is not necessary to account for category share as it is in industries (such as banking and insurance) where consumers could be multi-brand users. Third, the market is volatile and competitive: according to Gartner, ${ }^{21}$ about 23 per cent of French mobile phone service users switched providers in 1999 as did about 26 per cent in 2000 . The average revenue per unit was down to $\$ 563$ in 1999 from $\$ 1,395$ in 1995. Finally, the relationship with the service provider starts with the initial contract and we measure the customer retention after the period. In our data, we selected individuals who signed up for a 12-month binding contract.

Data include both survey and transaction measures of 1,493 customers observed from the starting date of subscription varying from May 1999 to December 2000. Survey results were obtained from a subscriber questionnaire administered by phone from January 2000 to March 2001. All individuals were surveyed between two and nine months after the start of their subscription. Customers who had signed up for one-year contract were randomly selected. No information about the refusal rate is communicated. In this period, the mobile phone service usage was being generalised. The proportion of male customers from our data sample explains this phenomenon as male proportion evolved from 80 per cent among survey respondents of January 1998 to 53 per cent of March 2001, which makes our sample dominated by male users ( 71 per cent). The average duration at the time of the survey was 5.8 months. The survey included a measure of satisfaction (overall satisfaction) and the magnitude of WOM intent (willingness to recommend). These items were measured on a 10-point scale.

Similar to results from other surveys, the satisfaction and loyalty measures are left skewed with a mean greater than 7 out of 10 -point scale $e^{3,22,23}$ In our data set, there are very few defections prior to the 12th month since the data set includes only customers who signed up for a one-year contract that binds them to pay the basic fee for 12 months, even if they drop the service before 12 months.

\section{Estimation of segment-level CLV}

As mentioned earlier, direct financial elements of revenue and costs should not be the only components that determine CLV. It is important to include the indirect effect of WOM in estimating CLV and we examine its impact in this section. In Table 2, we report four segments based on the level of WOM intent and that of monthly revenue in order to compare the lifetime value between high and low WOM intent segments aligned by the level of direct financial contribution. As for the WOM intent, we use a median split for high and low intent. For monthly revenue, we split customers based on their plan type of varying minutes. Customers having subscribed to a plan type less than 4 hours per month are assigned to low revenue segment, and customer with a longer plan type are assigned to high revenue segment. Among high revenue customers, the defection rate is lower in high WOM intent segment compared to low WOM intent segment by 4 per cent across periods, 20 to 16 per cent at 12 th month, and 72 to 68 per cent at 24th month. In terms of financial impact, the 4 per cent difference of defection rate will be substantial as reported in Reichheld, ${ }^{7}$ which showed huge financial gain resulted from the 5 per cent improved defection rate. Next, based on the current segment structure, we extend our model using simulation to show the long-run impact of WOM in calculating CLV. 
Augmenting simulation to actual data In this section, we construct a simulation model that estimates CLV by extending our model over time. We complement the actual data with other estimates obtained from secondary sources to compare the difference of lifetime value with and without integration of WOM effects. The following parameters are used to compute CLV of segments of high/ low revenue and high/low WOM intent.

In the simulation, the total duration (T) is fixed to five years. Four segments based on WOM intent and revenue contribution are applied. To capture the dynamics, the average annual growth rate of 37 per cent between 1999 and 2003, reported by

Table 1: Sample characteristics

\begin{tabular}{lrr}
\hline Variable & \multicolumn{1}{c}{ Mean } & \multicolumn{1}{c}{ s.d. } \\
\hline Total duration (month) & 18.25 & $(5.97)$ \\
$\begin{array}{l}\text { Duration at the moment of } \\
\text { survey (month) }\end{array}$ & 5.81 & $(1.81)$ \\
Defection rate at 12th month & 0.19 & $(0.39)$ \\
Defection rate at 24th month & 0.70 & $(0.46)$ \\
Monthly spending (FF) & 337.66 & $(248.13)$ \\
Overall satisfaction & 7.34 & $(1.58)$ \\
WOM intent & 7.45 & $(2.37)$ \\
\hline
\end{tabular}

Gartner $^{21}$ is used. As for the level of operating cost, we take 80 per cent of operation revenue that corresponds to one of global operator, Vodafone's level of operating cost (2001 annual report). And two different amounts of acquisition cost is applied, high revenue segments $(1,200$ French Francs (FF)) and low revenues segments $(600 \mathrm{FF})$ under an assumption to recover this initial investment within a year of the contract term. One-fifth of acquisition cost is imputed as remarketing cost following 5:1 ratio of acquisition and remarketing cost. ${ }^{24}$ For the direct impact of WOM on acquisition cost saving (WOM Saving), we apply 16.4 per cent, which is based on the average of Forrester Research Report. ${ }^{25}$ To include the effect of WOM on the retention of customers, we include the defection rate at the 12th month of each segment based on the actual company data reported in Table 2. To discount the future revenue and cost, 5 per cent of market average interest rate is used.

Table 3 reports simulation results that compare the estimate of CLV with and

Table 2: Classification by revenue and WOM intent

\begin{tabular}{llll}
\hline & & Mean & s.d. \\
\hline Low revenue & & & \\
Low WOM intent $(N=347)$ & Defection rate at 12th month & 0.41 \\
& Defection rate at 24th month & 0.22 & 37 \\
& Monthly spending (FF) & 0.72 & 1.57 \\
& Overall satisfaction & 210 & 1.90 \\
& WOM intent & 6.42 & 0.39 \\
High WOM intent $(N=448)$ & Defection rate at 12th month & 5.25 & 0.46 \\
& Defection rate at 24th month & 0.18 & 39 \\
& Monthly spending (FF) & 0.70 & 1.08 \\
& Overall satisfaction & 211 & 0.92 \\
High revenue & WOM intent & 8.13 & 9.04 \\
Low WOM intent $(N=283)$ & & & 0.40 \\
& Defection rate at 12th month & 0.20 & 0.45 \\
& Defection rate at 24th month & 0.72 & 283 \\
& Monthly spending (FF) & 487 & 1.62 \\
& Overall satisfaction & 6.26 & 1.89 \\
High WOM intent $(N=415)$ & WOM intent & 5.20 & 0.37 \\
& Defection rate at 12th month & 0.16 & 0.47 \\
& Defection rate at 24th month & 313 \\
& Monthly spending (FF) & 0.68 & 1.15 \\
& Overall satisfaction & 879 & 0.91 \\
\hline
\end{tabular}


实 Lee, Lee and Feick

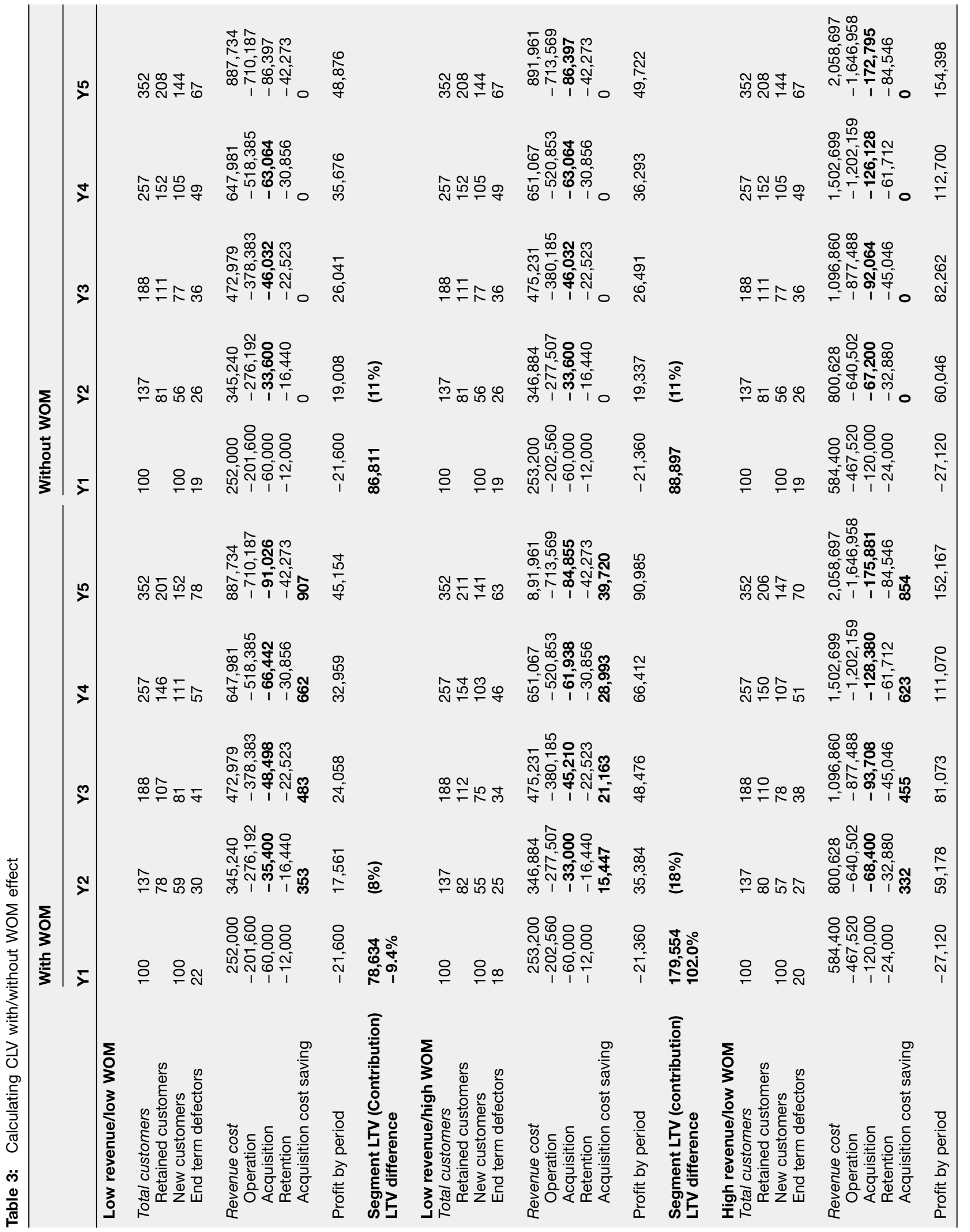




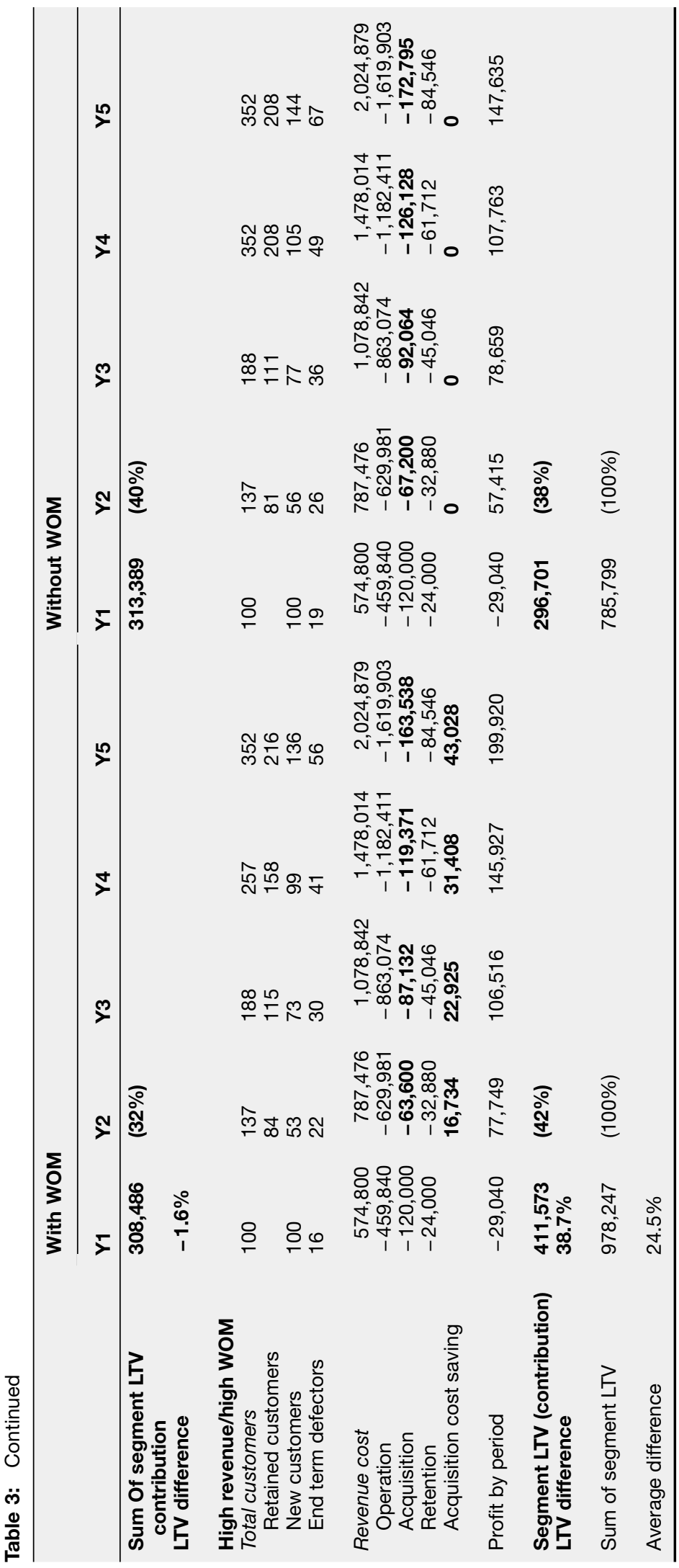

without referral and compare the percentage differences across four segments of revenue/ referral intent. We assume no impact of WOM for period 1 as there is no customer base in the first period. In addition, we assume that there is no change in segment share over five-year span and that segment size changes are due only to the market growth rate of 37 per cent per year. Therefore, a higher defection rate implies that the firm needs to recruit more new customers to maintain the share equal to the base size plus market growth.

The impact of WOM on CLV is introduced in two ways: direct savings in acquisition cost (shown in acquisition cost saving of each segment in Table 3) and increased customer retention (the difference of acquisition cost between with/without WOM in Table 3). While the former is always positive for all segments depending on the level of WOM intent of each segment, the latter could be positive or negative as it is normalised to the average defection rate at the aggregate level. In other words, only segments having lower defection rate than the average receive a positive WOM impact on CLV. For the direct savings in acquisition cost, 224 new customers are acquired in total $(59,55,57$, and 53 for each segment) in Year 2 and it costs 600 FF for low revenue segment customers and 1,200 FF for high revenue segment ones which results in 200,800 FF in total $(35,400,33,000,68,400$, and 63,600 for each segment). As this direct saving addresses to all new customers regardless of their revenue size, the service provider can save 16.4 per cent of this spending $(32,866$ FF) on acquisition if it takes WOM savings into account. On the other hand, the direct saving of acquisition cost varies by segment with their WOM intent transformed by logit ratio in Equation (1): 1.1 per cent for low REV/low WOM segment, 47.0 per cent for low REV/high WOM, 1.0 per cent for high REV/low WOM, and 50.9 per cent for high REV/high WOM. 
Out of total direct savings of $32,866 \mathrm{FF}$ generated by WOM, 353 FF, 15,447 FF, 332 FF, and $16,734 \mathrm{FF}$ are contributed by each segment: Under the current simulation setting, which assumes the same growth rate of customers in each segment, more new customers need to be acquired if a segment had higher defection rate than others, and that is why the number of total customers is same for all segment across all periods. For example, a low REV/high WOM segment has to acquire only 55 compared to 59 for low REV/low WOM intent segment. It spends less money on customer acquisition, 33,000 FF, for low REV/high WOM segment compared to that, 35,400 $\mathrm{FF}$, for low REV/low WOM intent segment.

By integrating WOM impact, the lifetime value of high WOM intent segments increases substantially. For low REV/high WOM intent segment, the increase of CLV is by 102.0 per cent from 88,897 to 179,554. For high REV/high WOM intent segment, the increase is by 38.7 per cent from 296,701 to 411,573 . On the other hand, CLV is reduced in low WOM intent segments because there is little increase through WOM and their defection rate is higher than high intent segments.

Note that, especially for the segment with low REV/high WOM, a substantial size of CLV can be gained. The greatest impact of WOM appears in the low REV/ high WOM segment. This segment probably would not be profitable enough to attract the attention of managers if they rely on the traditional view of CLV. As shown in the 'without WOM' column in Table 3, its lifetime value contribution accounts for only 11 per cent of total lifetime value. With the incorporation of WOM effects, it accounts for about 18 per cent of the total lifetime value due to its high level of WOM intent that reduces acquisition costs directly and indirectly through the reduced defection rate. The substantial difference of CLV in low REV/high WOM segment should underscore the importance for managers to incorporate latent elements such as WOM into CLV management. The current CLV framework, which only takes into account direct financial contributions, bears a potential risk of underestimating the true value of customers who can contribute indirectly by generating positive WOM.

\section{WOM impact under varying market conditions}

In the previous section, our analysis focused on segment level impact of WOM based on actual company data, but limited in terms of market growth rate and the level of competition. We extend our findings showing how the impact of WOM varies as the firm faces different market situations of growth rate and competition level. Firms typically pay more attention to customer acquisition than to customer retention while the market is growing rapidly. It is important for firms to be able to attract new customers as a means of generating growth. ${ }^{26}$ As market saturates, however, firms grow by attracting competitors' customers while keeping its own. Under these conditions, competition focuses on gaining market penetration and customer retention. It is thus useful to think about the extent of market growth and competition as important market contingencies that influence the impact of WOM. Using simulation, we compare the mixed impact of WOM on lifetime value under varying market growth rate and level of competition.

Figure 1 illustrates simulation results in which we show the impact of varying the level of competition with annual churn rate and market growth rate with the percentage difference on CLV with and without WOM effects. It shows that WOM has a bigger impact on the CLV estimates as the defection rate goes up and as the market grows fast, all else being equal. Thus, it becomes critical to manage WOM in a market facing high competition and high 


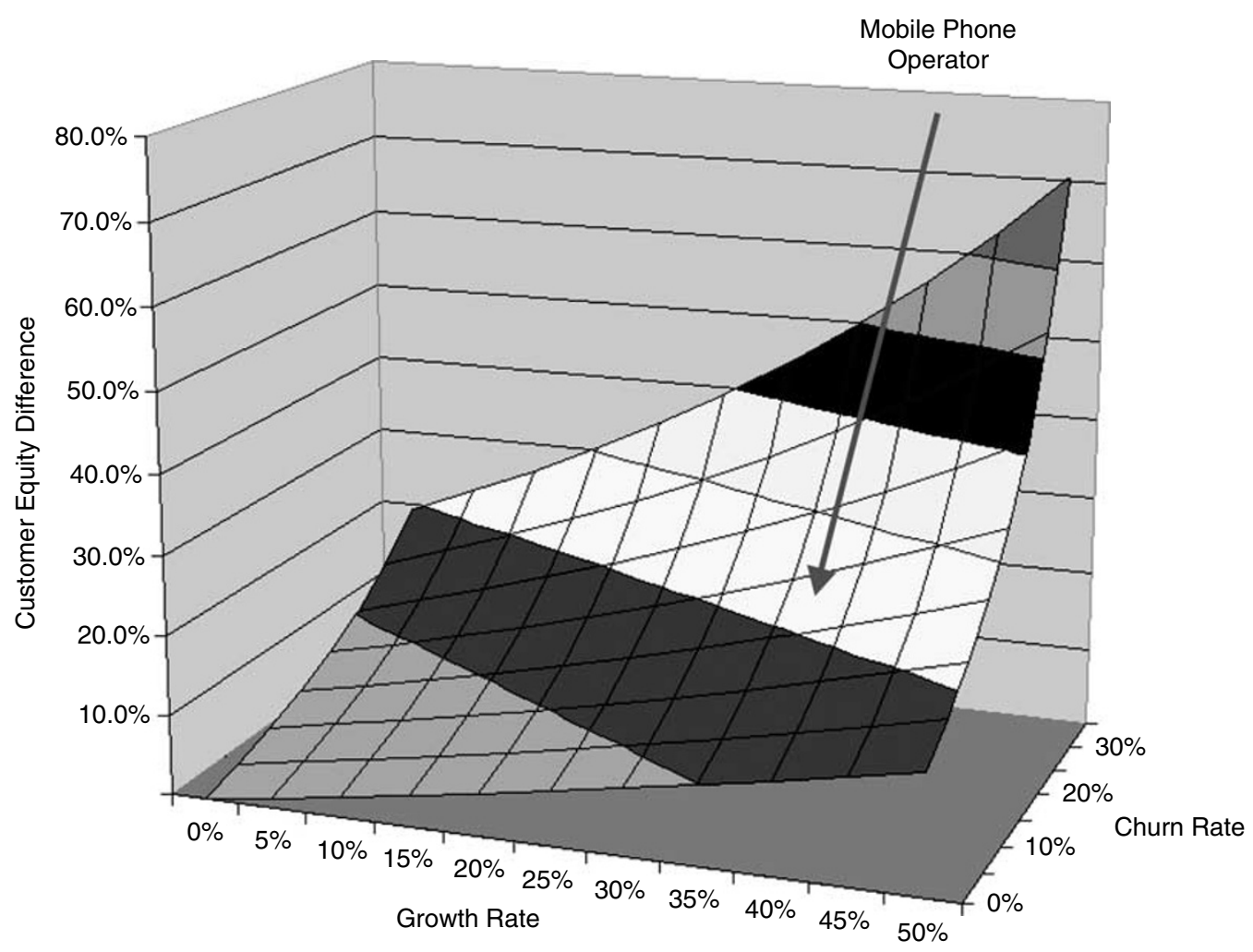

Figure 1: Impact of churn rate and market growth on CLV with/without WOM

growth. Note that these results follow the conventional wisdom that customer retention becomes the dominant task in the saturated market. Greater competition could come from a variety of sources: the existence of powerful firms in the marketplace because of concentration, increasing homogeneity of tastes or needs on the part of consumers, greater homogeneity of products produced by providers, or lower switching costs. ${ }^{2}$ Under any of these market conditions, we would expect to have increased churn rate and therefore, more notable effect of WOM.

The market growth rate can be seen as a reflection of the product lifecycle stage; for example, a higher growth rate early in the lifecycle. Our results showing the importance of WOM is thus consistent with the findings of the diffusion literature which emphasise the role of interpersonal influence in product diffusion early in the lifecycle. ${ }^{27,28}$ The result is also consistent with the social contagion theory that emphasises the role of WOM in the early stages of the lifecycle in helping the product take off. ${ }^{26}$

\section{DISCUSSION}

In this paper, we have examined the importance of incorporating the WOM effect in estimating CLV. The lifetime value of customers increases more through direct savings of acquisition cost and extended duration as customers generate more positive WOM. By assessing the contribution of WOM to CLV, we have further confirmed the economics of customer loyalty ${ }^{7}$ and extended the perspective of previous research on WOM. $^{18,19,29}$ Our approach to integrate WOM effect into CLV complements other approaches to CLV management as prioritising investment in customers. 
Reward programmes, for example, are routinely affected by lifetime value estimates. ${ }^{30}$ We argue that, if only direct financial contributions are incorporated in CLV estimation, companies run the risk of missing the latent aspect of customer value and thus misjudge customers' true lifetime value. To maximise the lifetime value of customers, it is necessary to evaluate customers incorporating the indirect effects of WOM, and then invest accordingly to enhance customers' willingness to generate positive WOM. Our findings are particularly germane for the industry in which WOM is a major information source for purchases. Oftentimes, service providers are more subject to intangibles than producers ${ }^{15}$ and potential customers use the experience of existing customers as the information source for their own. ${ }^{13}$

In the current study, we have focused on estimating the impact of WOM on CLV through its effects on savings of acquisition costs. Because of the limited data availability, we used an attitudinal rather than behavioural measure of WOM. Our findings are limited in the sense that (i) we could not examine the negative WOM, (ii) if extremely positive WOM creates unreasonable expectations, it might lead to cognitive dissonance, resulting in higher defection rates.

We believe the underlying principle of the proposed approach is intact when we further incorporate actual tracking-based referral instead of survey measurement. Also, since we only had access to limited information on company costs and market conditions, we had to use a number of assumptions that may not be necessary in applying the proposed model. Finally, it would be useful to know if customers who are acquired by referral are more or less profitable compared to those acquired by traditional marketing efforts such as advertising since it will affect the CLV of customers acquired by different sources.

\section{References}

1 Bolton, R. N. (1998) 'A dynamic model of the duration of the customer's relationship with a continuous service provider', Marketing Science, Vol. 17, No. 1, pp. 45-65.

2 Jones, T. O. and Earl Sasser Jr., W. (1995) 'Why satisfied customers defect', Harvard Business Review (March-April), pp. 56-69.

3 Anderson, E. W. and Sullivan, M. W. (1993) 'The antecedents and consequences of customer satisfaction for firms', Marketing Science, Vol. 12, No. 2, pp. 125-143.

4 Anderson, E. W. and Vikas, M. (2000) 'Strengthening the satisfaction-profit chain', Journal of Service Research, Vol. 3, No. 2, pp. 107-120.

5 Reinartz, W. J. and Kumar, V. (2000) 'On the profitability of long-life customers in a noncontractual setting: An empirical investigation and implications for marketing', Journal of Marketing, Vol. 15(October), pp. 17-35.

6 Rust, R. T., Zahorik, A. and Keiningham, T. L. (1995) 'Return on quality (ROQ): Making service quality financially accountable', Journal of Marketing, Vol. 59(April), pp. 58-70.

7 Reichheld, F. F. (1996) 'The loyalty effect', Harvard Business School Press, Boston.

8 Berger, P. D. and Nasr, N. I. (1998) 'Customer lifetime value: Marketing models and applications', Journal of Interactive Marketing, Vol. 12, No. 1, pp. 16-30.

9 Blattberg, R. C. and Deighton, J. (1996) 'Manage marketing by the customer lifetime value test', Harvard Business Review (July-August), pp. 136-144.

10 Jain, D. and Singh, S. S. (2002) 'Customer lifetime value research in marketing: A review and future directions', Journal of Interactive Marketing, Vol. 16, No. 2, pp. 34-46.

11 Katz, E. and Lazarsfeld, P. (1955) 'Personal influence', The Free Press, New York, NY.

12 Zeithaml, V. A. and Bitner, M. J. (2003) 'Services marketing', 3rd Edition, McGraw Hill, New York, NY.

13 Bansal, H. S. and Voyer, P. A. (2000) 'Word-of-mouth processes within a services purchase decision context', Journal of Service Research, Vol. 3(November), pp. $166-177$.

14 Brown, J. J. and Reingen, P. H. (1987) 'Social ties and word-of-mouth referral behavior', Journal of Consumer Research, Vol. 14(December), pp. 350-362.

15 Murray, K. B. and Schlacter, J. L. (1990) 'The impact of services versus gods on consumers' assessment of perceived risk and variability', Journal of the Academy of Marketing Science, Vol. 18, No. 1, pp. 51-65.

16 Walker, J. L. (1995) 'Service encounter satisfaction: Conceptualized', Journal of Services Marketing, Vol. 9, No. 1, pp. 5-14.

17 Heskett, J. L., Earl Sasser Jr, W. and Schlesinger, L. A. (1997) 'The service profit chain', The Free Press, New York.

18 Bowman, D. and Narayandas, D. (2001) 'Managing customer-initiated contacts with manufacturers: The impact on share of category requirements and wordof-mouth behavior', Journal of Marketing Research, Vol. 38(August), pp. 281-297. 
19 Anderson, E. W. (1998) 'Customer satisfaction and word of mouth', Journal of Service Research, Vol. 1, No. 1, pp. 5-17.

20 Dwyer, R. F. (1997) 'Customer lifetime valuation to support marketing decision making', Journal of Direct Marketing, Vol. 11, No. 4, pp. 6-13.

21 Gartner (2000) Mobile Services October 2000 update: France.

22 Fornell, C. (1992) 'A national customer satisfaction barometer: The Swedish experience', Journal of Marketing, Vol. 56(January), pp. 1-21.

23 Narayandas, D. (1998) 'Measuring and managing the benefits of customer retentions: An empirical investigation', Journal of Service Research, Vol. 1, No. 2, pp. $108-128$.

24 Peters, T. (1988) 'Thriving on chaos', Alfred A. Knopf, New York, NY.
25 Forrester Research (2000) Technographics Survey Bechmark 'Europe' April 2000.

26 Hogan, J., Lemon, K. N. and Libai, B. (2003) 'What is the true value of a lost customer?', Journal of Service Research, Vol. 5(February), pp. 196-208.

27 Bass, F. (1969) 'A new product growth model for consumer durables', Management Science, Vol. 15 (January), pp. 215-227.

28 Mahajan, V. and Wind, Y. (1986) 'Innovation Diffusion Models of New Product Acceptance', Ballinger Publishing Company, Cambridge, MA.

29 Richins, M. L. (1983) 'Negative word of mouth by dissatisfied consumers: A pilot study', Journal of Marketing, Vol. 47(Winter), pp. 68-78.

30 Reinartz, W. J. and Kumar, V. (2002) 'The mismanagement of customer loyalty', Harvard Business Review (July), pp. 4-12. 